\title{
Comorbid epilepsy in Finnish patients with adult-onset Huntington's disease
}

Jussi O. T. Sipilä ${ }^{1,2^{*}}$, Merja Soilu-Hänninen ${ }^{1,2}$ and Kari Majamaa ${ }^{3,4}$

\begin{abstract}
Background: Seizures are common in juvenile Huntington's disease (HD), but considered to be rare in adultonset HD. We studied the occurrence of epilepsy and seizures in a nationwide cohort of Finnish patients with adult-onset HD.

Methods: Patients with HD and their diagnoses of epilepsy or seizures were identified by a search into a nationwide registry. Cases were verified in a subsequent review of patient charts.

Results: Three out of 114 HD patients alive on prevalence date had been diagnosed with epilepsy giving a prevalence of $2.6 \%$ (95\% Cl, 0.6-7.5). In addition, one patient with a single unprovoked seizure, one patient with a medication-induced seizure and two patients with transient nonspecific attacks were identified. Epilepsy was not associated with clinical severity of HD and seizures were controlled with antiepileptic medications (AEDs). Generalized tonic-clonic seizures (GTCs) were the most common seizure type.
\end{abstract}

Conclusions: Prevalence of epilepsy is similar in patients with adult-onset HD compared to general population. Seizures are easily controlled with AEDs.

Keywords: Antiepileptic drug therapy, Clinical neurology, Epileptic seizures, Huntington's disease, Neurodegenerative disorders, Neurologic manifestations

\section{Background}

Epileptic seizures are common in juvenile-onset Huntington's disease (HD), where they occur at a frequency of $38 \%$ [1]. The seizures are most often of the generalized tonic-clonic (GTC) type followed by tonic, myoclonic and staring spells [1-3]. On the other hand, seizures are thought to be rare in adult-onset HD and, even more, it has been proposed that the clinical diagnosis of HD should be re-evaluated, if seizures occur in an adult patient [4]. However, research on the subject is scarce, as the occurrence of seizures and epilepsy in adult-onset HD has not been thoroughly investigated since the introduction of genetic testing for $\mathrm{HD}$ in 1993. We examined the incidence of epilepsy and seizures in a nationwide cohort of Finnish patients with adult-onset HD.

\footnotetext{
* Correspondence: jussi.sipila@utu.fi

${ }^{1}$ Division of Clinical Neurosciences, Turku University Hospital, POB 52 Fl-20521 Turku, Finland

${ }^{2}$ Neurology, University of Turku, Turku, Finland

Full list of author information is available at the end of the article
}

\section{Methods}

We have recently reported on the ascertainment of a national cohort of patients with HD through a search in the Finnish Care Register for Health Care and outpatient benchmarking database [5]. These registries are maintained by the National Institute of Health and Welfare (THL) and cover all public hospitals and health centers in Finland. Patients treated for adult-onset HD between the years 1987-2010 were identified $(N=206$, of whom 162 were genetically confirmed) and their patient charts were reviewed for clinical and genetic information. The mean age at HD diagnosis was 53.2 years and the mean age at death was 60.9 years $(N=104)$. The median follow-up since HD diagnosis was 7.6 years (range 0.623.8 years) and mean age at the end of follow-up was 61.2 years (range 28.0-86.0 years). On the prevalence date (31 December, 2010) 114 patients were alive.

The two THL registries were then searched for the seizure-designated codes R56.8 and G40-G42 among the 206 HD patients and their clinical charts were reviewed by JS. Patients were deemed to be eligible, if the 
attending neurologist had made the diagnosis of epilepsy or epileptic seizure. Active epilepsy was defined as a patient with epilepsy having had seizures during the last 5 years. All the cases with seizures identified in the database search could be confirmed in the chart review and, in addition, no non-coded cases were encountered. The study was approved by the ethics committee of the Hospital District of Southwest Finland (19/180/2010) and national authorization was given by the THL (STM/ $3375 / 2010)$.

\section{Results}

\section{Incidence of epilepsy}

Four patients had been diagnosed with epilepsy. One of these patients had only experienced one seizure and was not considered to have epilepsy in this study. For the three remaining patients, the median age at HD diagnosis was 49 years (range, 35-76 years), which did not differ from that in patients without epilepsy (52 years; range, 23-82 years) ( $p=0.89$, Mann-Whitney $\mathrm{U}$ test). The prevalence of diagnosed epilepsy among living HD patients on the prevalence date was $2.6 \%$ (95\% confidence interval 0.6-7.5\%) and the prevalence of active epilepsy was $0.9 \%$ (95\% CI 0.0-4.8\%). The crude incidence of epilepsy was 24/100,000 person-years.

\section{Patient I}

Patient I presented with three episodes of impaired consciousness considered epileptiform at the age of 56 years (Table 1). EEG and brain CT were normal. He was diagnosed with temporal lobe epilepsy and carbamazepine (CBZ) resulted in complete seizure control. Later CBZ was switched to phenytoin (PHT), but the reason for this change was not documented. HD was diagnosed at the age of 76 years on the basis of balance impairment, dyskinesias and chorea. He had no family history of HD, but his father had exhibited similar motor symptoms late in life. PHT was discontinued after a 20-year seizurefree period and no new seizures occurred during the 9 years of follow-up.

\section{Patient II}

Patient II had presented with seizures in the course of an appendicitis at the age of 11 years and in association with alcohol use at the age of 20 years. At the age of 33 years an unprovoked GTC occurred followed by aggressive behavior for half an hour before returning to normal consciousness. EEG revealed an irritative pattern in the form of irregular intermediate velocity complexes with sharp waves on the left and short paroxysms after hyperventilation. Brain CT showed local atrophy in the right temporal region, which was considered a possible sequel of a childhood trauma. Slow-release CBZ resulted in complete seizure control. Withdrawal of CBZ was attempted twice after a 10-year seizure-free period and a normal EEG. Seizures recurred on both occasions, but were again well controlled after reinstitution of CBZ. No new clinical seizure activity occurred during the 11 years of follow-up after the second reinstitution of $\mathrm{CBZ}$ at the age of 47 years.

At the age of 49 years the patient was evaluated because of cognitive and behavioral problems. Marked hyperkinesia, clumsiness, impairment of saccade initiation and motor impersistence along with poor insight suggested the diagnosis of HD. Indeed, his grandmother, mother, maternal uncle and aunt had been diagnosed with HD and the patient also received the diagnosis. However, genetic testing was never performed. The patient was institutionalized at the age of 54 years because of progression of HD.

\section{Patient III}

Patient III was diagnosed with HD at the age of 35 years on the basis of depression, clumsiness, cognitive deterioration, chorea and a family history of HD. At the age of 40 years she presented with an attack during which she gasped, drooled and was unresponsive though her eyes were open. There were no tonic-clonic movements. The attack occurred in the morning before waking up and lasted for $15 \mathrm{~min}$. Afterwards she was oriented but had no recollection of the events. EEG revealed several isolated spike-wave discharges over the convexity, some of which were associated with muscle jerks. Unspecified epilepsy was diagnosed, but no AED was instituted. Four months later she was admitted because of worsening of startle-type muscle spasms. Slow-release valproic acid was initiated resulting in significant improvement. The patient did not attend follow-up visits.

Table 1 Characteristics of Finnish Huntington's disease patients with epileptic seizures

\begin{tabular}{|c|c|c|c|c|c|c|c|c|c|}
\hline \multirow[b]{2}{*}{ Patient } & \multirow[b]{2}{*}{ Gender } & \multirow[b]{2}{*}{ Inheritance } & \multicolumn{2}{|l|}{ Repeat length } & \multicolumn{2}{|l|}{ Age (years) at } & \multirow[b]{2}{*}{ Medication } & \multirow[b]{2}{*}{ Tapering off } & \multirow[b]{2}{*}{ Age at death } \\
\hline & & & CAG (affected) & CAG (wild type) & HD diagnosis & $\begin{array}{l}\text { Seizure } \\
\text { onset }\end{array}$ & & & \\
\hline I & Male & Paternal & 40 & 19 & 76 & 56 & $\mathrm{CBZ}$, later $\mathrm{PHT}$ & Successful & 85 \\
\hline$\|$ & Male & Maternal & n.d. & n.d. & 49 & 33 & CBZ & 2 Attempts, unsuccessful & \\
\hline$\|$ & Female & Maternal & 44 & 17 & 35 & 40 & VPA & n.a. & \\
\hline
\end{tabular}

n.a. not attempted, n.d. not determined, CBZ Carbamazepin, PHT Phenytoin, VPA Valproic acid 


\section{Patients with seizures and nonspecific paroxysmal symptoms}

A woman, aged 32 years, experienced a tonic-clonic seizure. Slow-release CBZ was initiated and no further seizures were recorded during the 9 years of follow-up. In the year following the GTC, she was diagnosed with $\mathrm{HD}$, the symptoms of which had begun at the age of 21 years. Another woman, aged 56 years, experienced one tonic-clonic seizure followed by transient decrease in blood pressure 10 years after she had received the diagnosis of HD. At the time of the seizure, she was being treated for respiratory tract infection with clarithromycin, which was assumed to have increased the blood concentration of clozapine. Blood levels were not measured. Clarithromycin was discontinued and seizures did not recur in 5 years of follow-up despite the use of clozapine.

Two other patients (one man) reported repeated short spells of decreased awareness and attention including memory disruption. Their EEG studies revealed no pathological findings. Valproic acid was initiated for the male patient, but no change in the attack frequency was evident when on or off the medication. No diagnosis of epilepsy was confirmed and the attacks abated within 3 years in both cases.

\section{Discussion}

We found that the point prevalence of diagnosed epilepsy in our cohort of adult-onset HD patients was $2.6 \%$ (95\% CI 0.6-7.5\%). The prevalence of active epilepsy was $0.9 \%$ (95\% CI 0.0-4.8\%), which is rather similar to the prevalence of $0.6 \%$ (95\% CI 0.61-0.65\%) reported for the Finnish general adult population [6].

The phenotype of adult-onset HD differs markedly from that of juvenile $\operatorname{HD}[2,3,7]$. Seizures are a wellestablished part of juvenile HD [1-3] but rare in adult-onset HD [4]. Our results support this view. The available information is not sufficient to explain the higher seizure susceptibility in juvenile HD compared to that in the adult-onset disease [8], but it is important to note the marked inverse association between seizure risk and age of onset in juvenile HD [1, 2, 9]. A literature survey performed prior to the introduction of genetic testing for HD has revealed that $90 \%$ of patients have seizures, if the onset of HD is before 5 years of age. This proportion decreases to $52 \%$ among patients with age of onset between 11 and 20 years [9]. Furthermore, it has been reported that the mean age of HD onset is 5 years lower in juvenile HD patients with seizures than that in patients without seizures [1] and that only those with disease onset younger than 10 years develop seizures [2].

Although the Finnish Care Registers have been found to be reliable [10], the retrospective setting of the study entails that we may have missed cases with seizures. The generalizability of our results may also be limited by the fact that prevalence of HD in Finns is lower than that in many other European populations $[5,11]$.

\section{Conclusions}

Our findings suggested that, contrary to juvenile HD, epilepsy is an infrequent and easily controlled comorbidity in adult-onset HD. GTC was the seizure type most often observed in our patients. Our adult-onset patients responded uniformly well to medication and seizure freedom was achieved with the first AED prescribed. We found no difference in the prevalence of epilepsy when comparing patients with adult-onset HD to general population.

\section{Availability of supporting data}

No additional data available

\section{Competing interests}

Jussi O.T. Sipilä has received a honorarium (Boehringer-Ingelheim), has received travel grants (Orion Corporation, Merck Serono, Sanquin, Lundbeck) and holds shares (Orion Corporation).

Merja Soilu-Hänninen has received travel grants, honoraria and consulting and investigator fees (Astra-Tech, Bayer, Biogen-Idec, Eisai, Genzyme, GSK, Lundbeck, Merck, Novartis, Orion Corporation, Sanofi-Aventis, UCB).

Kari Majamaa has received travel grants (Teva).

\section{Authors' contributions}

JS and KM conceived and designed the study. JS acquired, analyzed and interpreted the data and wrote the manuscript draft. MS-H participated in analyzing and interpreting the data and writing the manuscript. KM interpreted the data, performed a part of the statistical analyses, participated in writing the manuscript and supervised the study. All authors read and approved the final manuscript.

\section{Acknowledgments}

This study was supported by grants from the National Graduate School of Clinical Investigation, Finnish Parkinson Foundation and VTR funding from Turku University Hospital.

\section{Author details}

${ }^{1}$ Division of Clinical Neurosciences, Turku University Hospital, POB 52, FI-20521 Turku, Finland. ${ }^{2}$ Neurology, University of Turku, Turku, Finland. ${ }^{3}$ Unit of Clinical Neuroscience, Neurology, University of Oulu, Oulu, Finland. ${ }^{4}$ Department of Neurology and Medical Research Center, Oulu University Hospital, Oulu, Finland.

Received: 4 August 2015 Accepted: 4 February 2016

Published online: 10 February 2016

References

1. Cloud LJ, Rosenblatt A, Margolis RL, Ross CA, Pillai JA, Corey-Bloom J, et al. Seizures in juvenile Huntington's disease: frequency and characterization in a multicenter cohort. Mov Disord. 2012;27:1797-800.

2. Gonzales-Alegre P, Afifi AK. Clinical characteristics of childhood-onset (juvenile) Huntington disease: a report of 12 patients and review of literature. J Child Neurol. 2006;21:223-9.

3. Rasmussen A, Macias R, Yescas P, Ochoa A, Davila G, Alonso E. Huntington disease in children: genotype-phenotype correlation. Neuropediatrics. 2000; 31:190-4.

4. Martino D, Stamelou M, Bhatia KP. The differential diagnosis of Huntington's disease-like syndromes: 'red flags' for the clinician. J Neurol Neurosurg Psychiatry. 2013;84:650-6.

5. Sipilä JOT, Hietala M, Siitonen A, Päivärinta M, Majamaa K. Epidemiology of Huntington's disease in Finland. Parkinsonism Relat Disord. 2015;21:46-9. 
6. Keränen T, Riekkinen PJ, Sillanpää M. Incidence and prevalence of epilepsy in adults in Eastern Finland. Epilepsia. 1989;30:413-21.

7. Walker FO. Huntington's disease. Lancet. 2007;369:218-28.

8. Imarisio S, Carmichael J, Korolchuck V, Chen CW, Saiki S, Rose C, et al. Huntington's disease: from pathology and genetics to potential therapies. Biochem J. 2008:412:191-209.

9. Brackenridge CJ. Factors influencing dementia and epilepsy in Huntington's disease of early onset. Acta Neurol Scand. 1980;62:305-11.

10. Sund R. Quality of the Finnish Hospital Discharge Register: a systematic review. Scand J Pub Health. 2012;40:505-15.

11. Pringsheim T, Wiltshire K, Day L, Dykeman J, Steeves T, Jette N. The incidence and prevalence of Huntington's disease: a systematic review and meta-analysis. Mov Disord. 2012;27:1083-91.

Submit your next manuscript to BioMed Central and we will help you at every step:

- We accept pre-submission inquiries

- Our selector tool helps you to find the most relevant journal

- We provide round the clock customer support

- Convenient online submission

- Thorough peer review

- Inclusion in PubMed and all major indexing services

- Maximum visibility for your research

Submit your manuscript at www.biomedcentral.com/submit
Biomed Central 